\title{
Contrastive Analysis of the Elision of Schwa in English Utterances by Chinese and Uyghur Learners of English
}

\author{
Tingbo Wang \\ College of Foreign Languages \\ Xinjiang Normal University \\ College of Foreign Languages \\ Xinjiang University of Finance \& Economics \\ Urumqi, Xinjiang, China
}

\author{
Huaying Chen* \\ College of Foreign Languages \\ Xinjiang Normal University \\ Urumqi, Xinjiang, China \\ e-mail: chenhuaying@163.net \\ Corresponding Author
}

\begin{abstract}
An acoustic study on the elision of schwa in English utterances produced by a native speaker of English, a Han Chinese learner of English, and a Uyghur learner of English is presented in this paper. With Praat software, three acoustic parameters - fundamental frequency, the first formant and the second formant - are measured with two tiers (syllables and words). Results show that the Uyghur produces the elision of schwa in the same way as the native speaker of English does while the Han Chinese produces the schwa in English poorly. It indicates that the English produced by learners are influenced by the transfer of their mother tongues. In addition, it shows that the second/third language speech acquisition is restricted by the first language phonological system.
\end{abstract}

Keywords- schwa; elision; first formant; second formant

\section{INTRODUCTION}

It is known that elision of schwa /a/ is regarded as the essence of English elision. For phoneticians, the most striking characteristic of vowels is the frequency of first formant (F1) and second formant (F2). The proximate ranges of $\mathrm{F} 1$ and $\mathrm{F} 2$ of the schwa /a/ in English produced by native speakers are $400 \mathrm{~Hz}-500 \mathrm{~Hz}$, and $1200 \mathrm{~Hz}-1600 \mathrm{~Hz}$ [1].

Information about the characteristics of English, Uyghur and Chinese both in sound-changes and pronunciation can be found in previous studies. English words of a sense-group appear in the following syllable structures: CVC, VC, CCV, $\mathrm{CV}$ (V - vowel, C - consonant). Therefore, the phenomena of liaison between consonants and vowels happen frequently. It is notified that English possesses evident division between stressed syllables and unstressed syllables, which is not only shown in a word but also between words [2]. This means stressed syllables convey key information while unstressed syllables had better be read lightly or missing. So elision of /a/ in connected speech in English is commonplace. In Uyghur, there are six forms of syllable: $\mathrm{V}, \mathrm{CV}, \mathrm{VC}, \mathrm{CVC}$, $\mathrm{CCV}$, and VCC. The acoustic fidelity is influenced by near consonants when the moment vowels and consonants are combining [3]. The major traits of modern Uyghur are melodious vowels and weakening of vowels. Apart from that, elision in Uyghur not only happens to consonants but also to vowels [4]. So it can be seen that Uyghur share some similar syllable structures with English; what is more, the elision of unstressed vowels is present in both Uyghur and English utterances [5].
However, there are no multiple consonants in syllable in Chinese, and the Chinese syllables have clear boundary as well as neat structure of CV. Moreover, vowels play a decisive role in expressing meaning in Chinese words. Since monosyllabic word is the basic form of Chinese phonemes, it is impossible that liaison appear between Chinese characters. The Chinese monosyllabic word doesn't have the separation of stressed syllables and unstressed syllables. Thus, it is safe to say that such phenomena as assimilation, weakening and elision may not exist in Chinese utterances [2].

Therefore, we can make an assumption that the Uyghur learners of English produce the elision of schwa /o/ in English utterances in the same way as the native speakers of English do; contrarily, the Han Chinese learners of English produce English schwa /a/ obviously in connected speech without elision.

\section{Methodology}

\section{A. Subjects}

One female speaker of English, one female Han Chinese speaker, and one female Uyghur speaker served as subjects. The native speaker of English from the United States aged 40 and was working as an English teacher at the college with the researchers at the time when the experiment was carried out. The two local learners of English, one being Han Chinese speaker and one being Uyghur speaker, were students of English major at the same college with the researchers, and both of the two were 22 years old. They were regarded as intermediate-level learners of college English.

\section{B. Stimuli}

The stimuli consisted of two sentences and one phrase with three types of elision of the schwa /o/: elision in liaison, elision in quick speech and elision influenced by weak form.

\section{Procedure}

Each speaker was presented with the sheet with the sentences and phrase on it, and asked to produce each one naturally. Recordings were handled with a computer in a quiet classroom. 


\section{Acoustic Measurements}

The recordings were analyzed using the Praat speech analyzing software (http://www.praat.org). The traditional conclusions by auditory studies for elision of the schwa /o/ were referenced by the present experiment. F0 (the fundamental frequency), F1 and F2 were measured to mark the existence of $/ \partial /$ in the uttered English sentences and phrase by the three subjects.

\section{RESULTS AND ANALYSIS}

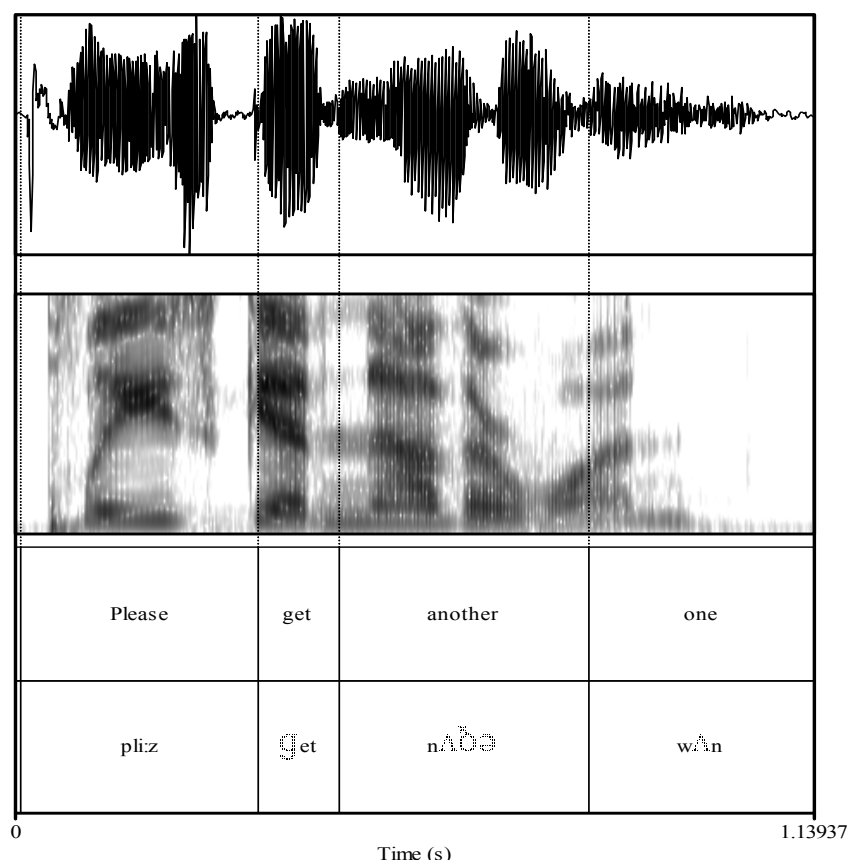

Figure 1. The first sentence produced by the native speaker of English.

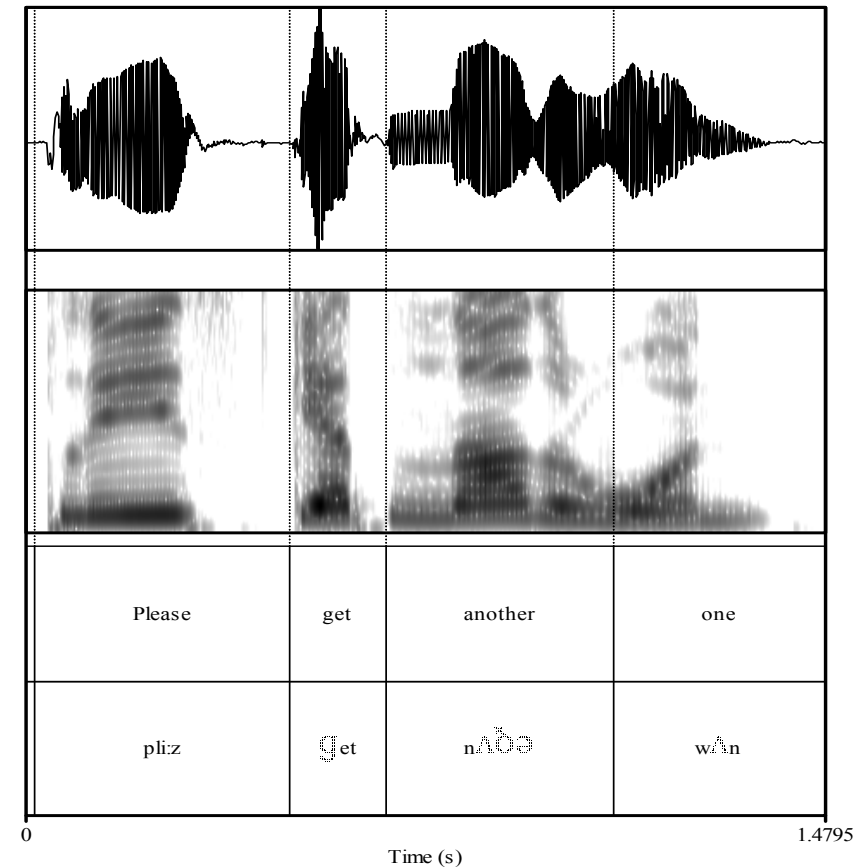

Figure 2. The first sentence produced by the Uyghur student

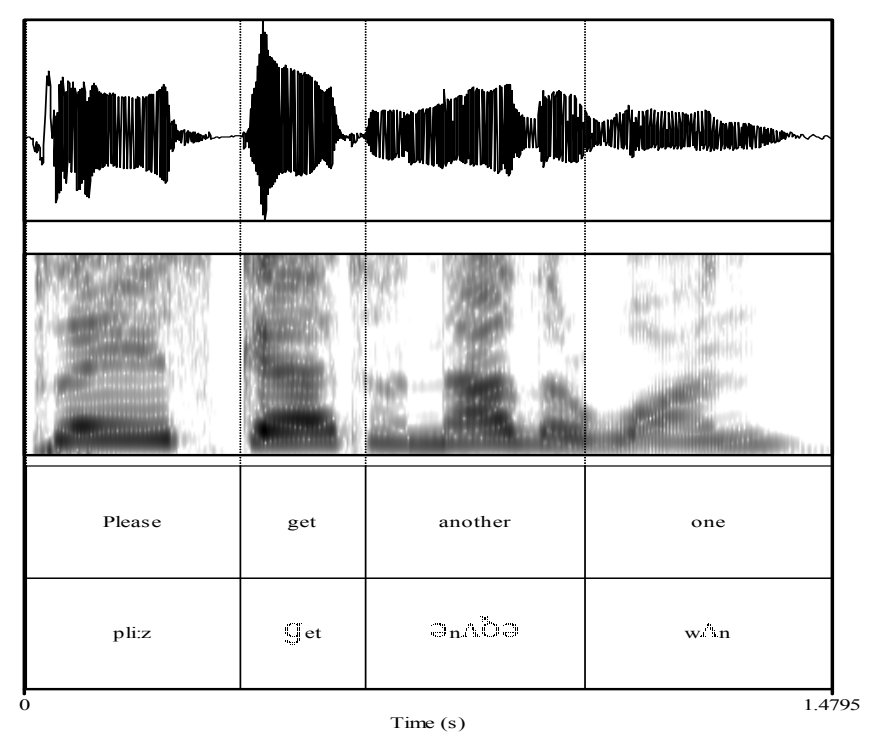

Figure 3. The first sentence produced by the Han student.

In Figures 1 and 2, the spectrograms show that the schwa $/ \mathrm{o} /$ between consonant $/ \mathrm{t} /$ and nasal $/ \mathrm{n} /$ is missing. The schwa $/ 2 /$ is reduced both by the native speaker of English and the Uyghur student under the condition of liaison. However, Figure 3 shows that there is a mid-central / $/$ / in the front of the word "another" produced by the Han student $(\mathrm{F} 0=273 \mathrm{~Hz}$, $\mathrm{F} 1=336 \mathrm{~Hz}, \mathrm{~F} 2=1632 \mathrm{~Hz}$ ). 


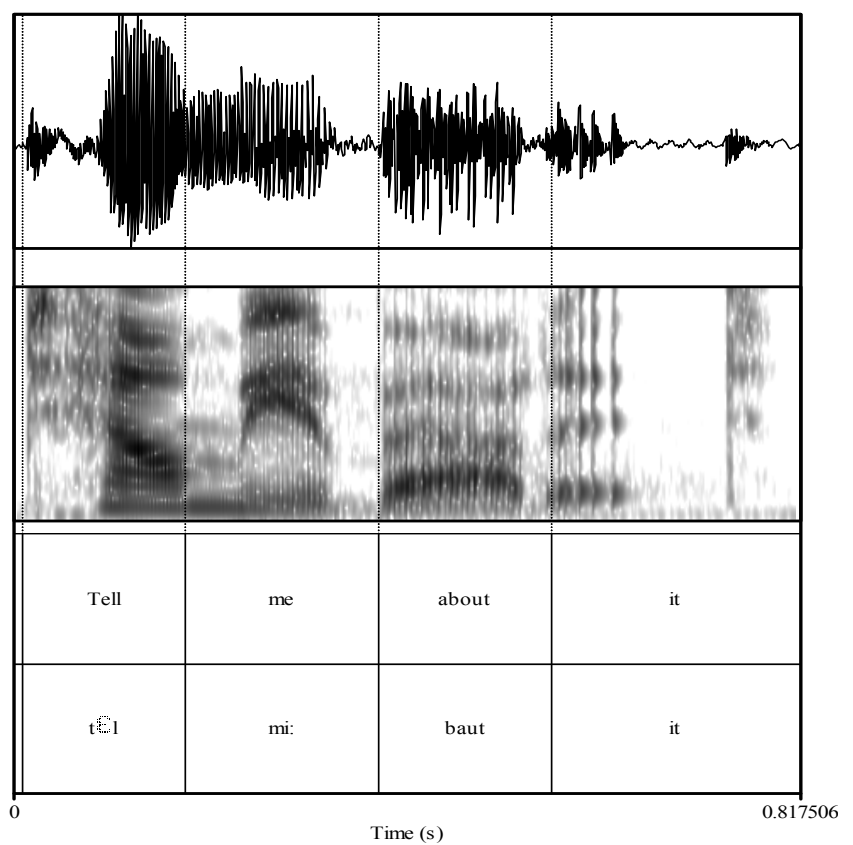

Figure 4. The second sentence produced by the native speaker of English.

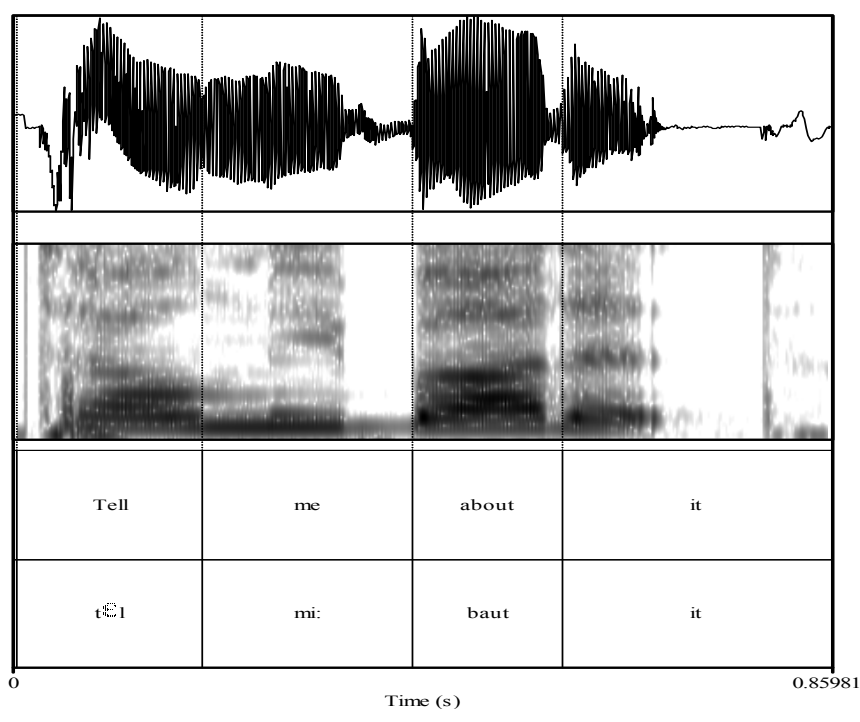

Figure 5. The second sentence produced by the Uyghur student.

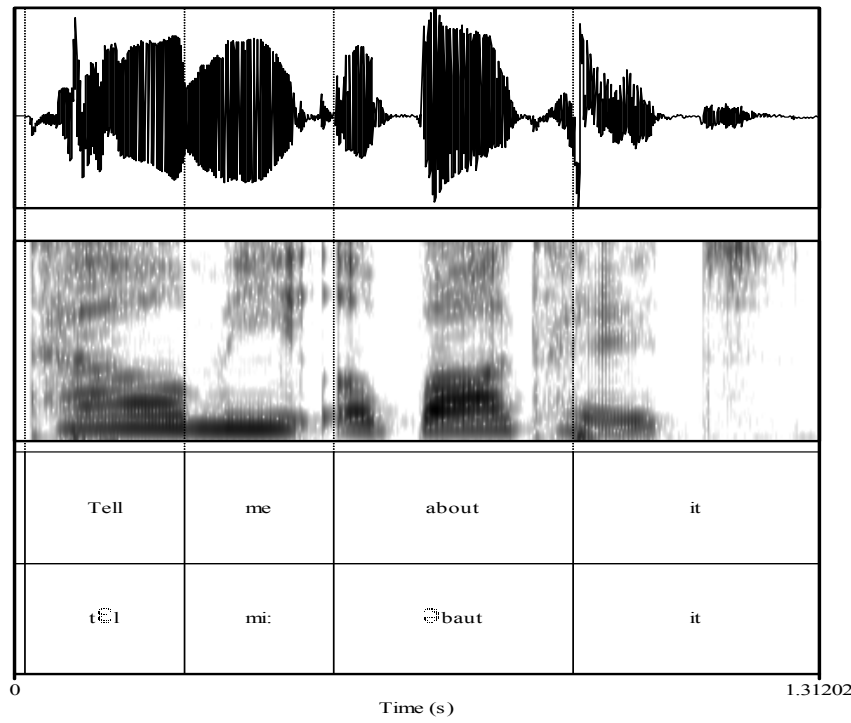

Figure 6. The second sentence produced by the Han student.

The spectrograms of Figures 4 and 5 show that the schwa $/ a /$ in the word "about" is missing in the sentences produced by both the native speaker of English and the Uyghur student. However, it is shown in Figure 6 that the schwa /a/ is pronounced without save effort by the Han student as it is certainly influenced by the Chinese phonology $(\mathrm{F} 0=246 \mathrm{~Hz}$, $\mathrm{F} 1=677 \mathrm{~Hz}, \mathrm{~F} 2=1290 \mathrm{~Hz})$.

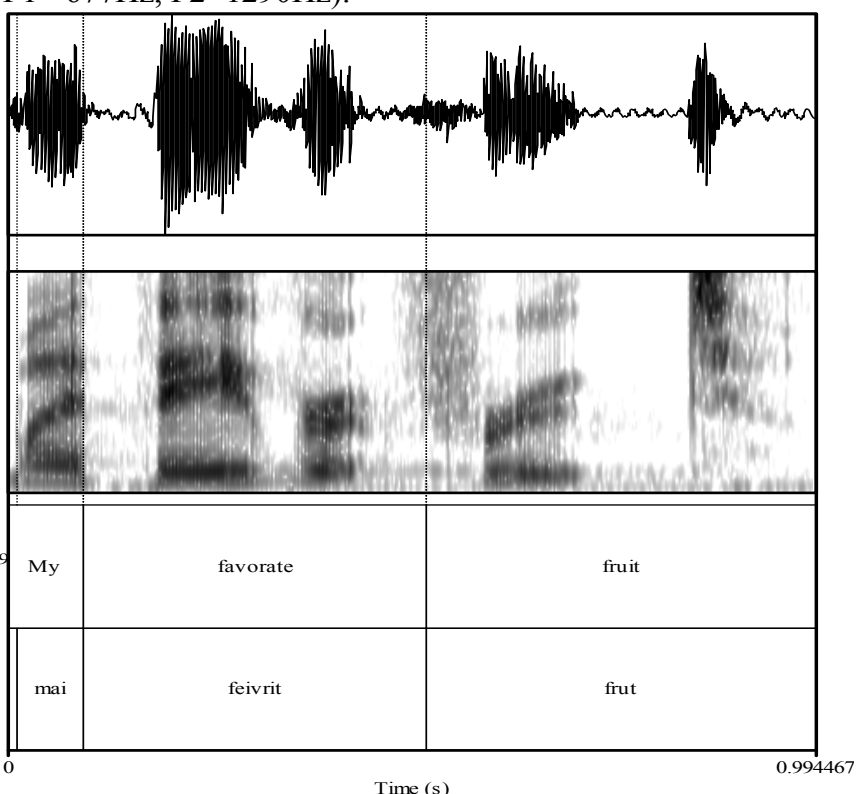

Figure 7. The phrase produced by the native speaker of English. 


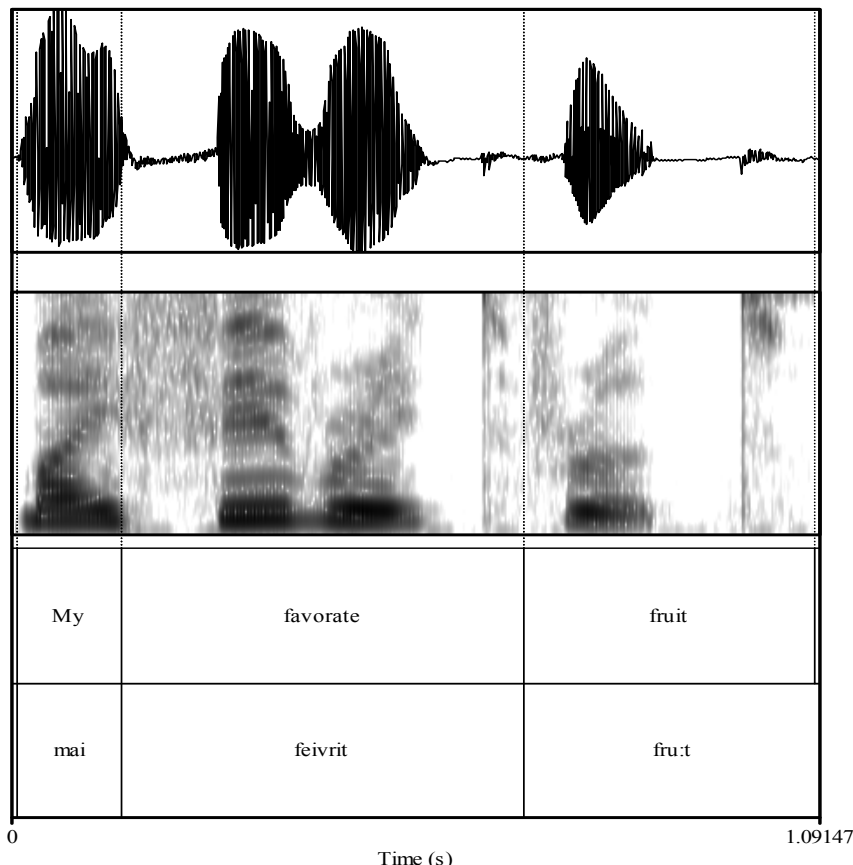

Figure 8. The phrase produced by the Uyghur student.

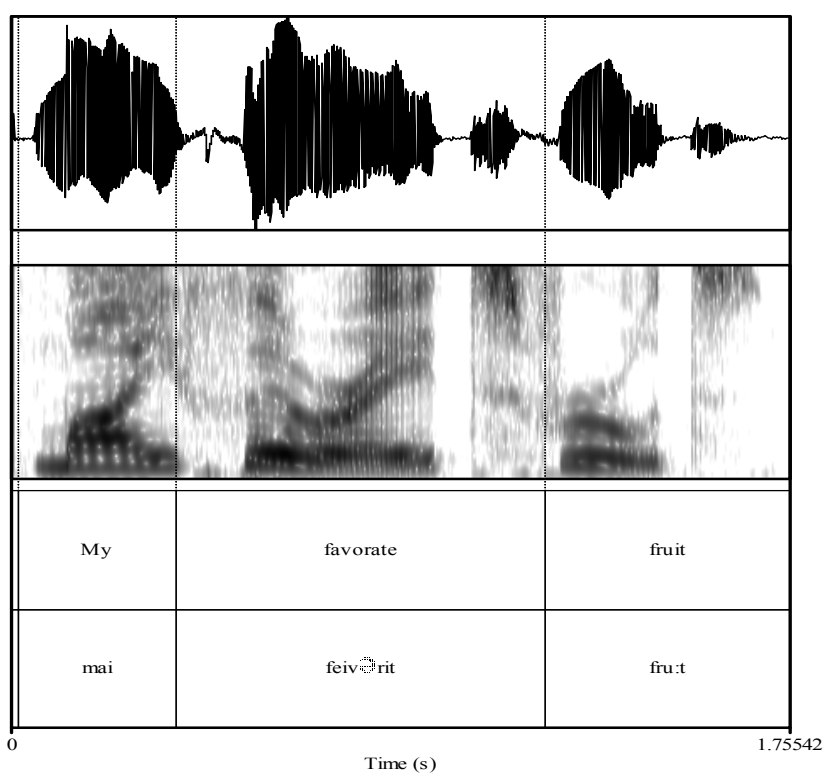

Figure 9. The phrase produced by the Han student.
Figures 7,8 and 9 show that the vowel/a/ in the word "favorite" is omitted by both the native speaker of English and the Uyghur student, but the Han student produces the phrase without losing any sound $(\mathrm{F} 0=191 \mathrm{~Hz}, \mathrm{~F} 1=558 \mathrm{~Hz}$, $\mathrm{F} 2=1385 \mathrm{~Hz}$ ), which can be explained by the influence of the Chinese syllable structure. Since in Chinese syllable structure the vowels including / $/$ /, which are the centers of syllables, play an important role, the Chinese students stress such phonemes in Chinese so as to present the meaning which the syllable stands for.

\section{CONCLUSION}

From the experiment above, it can be concluded that the way that the schwa /a/ is produced by the Han Chinese learners of English is obviously different from that of both the native speakers of English and the Uyghur learners of English. The Han Chinese learners of English produce English utterances syllable by syllable without the elision of schwa / /. The Uyghur learners of English produce the elision of schwa $/ \partial /$ in the same way as the native speakers of English do.

The differences are due to the interference of their respective first language phonology. As to the elision of schwa /o/, the Uyghur learners of English are positively influenced by the transfer of their mother tongue, while the Han Chinese learners of English are negatively influenced by the transfer of their mother tongue.

It is hoped that the results will have implications for English teaching and learning in Xinjiang, China.

\section{REFERENCES}

[1] K. Hayward, Experimental Phonetics. Britain: Pearson Education Limited, 2000.

[2] Y. Liu, "The Influence of Chinese on English," College English, issue 1, 2006, pp. 5-7.

[3] B. Yi, "The Experimental Analysis on Modern Uyghur," Language and Translation, issue 1, 2008, pp. 20-24.

[4] Z.Y. Xiao, The Languages in Xinjiang. Urumqi: Xinjiang People's Press, 1997.

[5] Z. L. Hu, Linguistics Coursebook. Beijing: Beijing University Press, 2001. 